\title{
ALCANCES PROCESALES DEL ENJUICIAMIENTO DE LAS ORGANIZACIONES CRIMINALES: UNA REVISIÓN DESDE LOS PRINCIPIOS DEL PROCESO
}

\author{
Juan Francisco Mendoza Perdomo \\ Universidad Católica de Colombia
}

\section{Resumen}

El artículo se ocupa de describir la aparición del colectivo de personas en el contexto de comisión del delito. Entendido aquel colectivo con la nomenclatura empírica de organización criminal, se plantea la cuestión de si el grupo puede ser un sujeto procesal para Derecho Penal. La respuesta a la inquietud utilizará el recurso epistemológico de los principios que disciplinan el sistema procesal penal colombiano.

Palabras clave: crimen organizado, delito de organización, capacidad procesal, principios

Autor: Abogado, doctorando en Derecho por la Universidad de Buenos Aires, profesor de Derecho Penal. Correo electrónico: juanframendoza@gmail.com

Recibido: 7 de septiembre de 2016; evaluado: 28 de noviembre de 2016; aceptado: 5 de diciembre de 2016. 


\title{
PROCEDURAL REACH OF THE CRIMINAL PROSECUTION OF CRIMINAL ORGANIZATIONS: \\ A REVIEW FROM THE STANDPOINT OF PROCEDURAL STRUCTURAL PRINCIPLES
}

\author{
Juan Francisco Mendoza Perdomo \\ Universidad Católica de Colombia
}

\begin{abstract}
The article describes a group of people in the context of criminal activity. Such group is understood to be part of a criminal organization. As such, the question of whether this group can be subject to criminal procedural law is raised. In order to answer this question we will use epistomiology resource of the principles that rule the Colombian criminal procedural system.
\end{abstract}

Keywords: Criminal Law, specific capacity, crime, organization, equality.

About the author: Lawyer, doctorate student at Universidad de Buenos Aires, Criminal Law professor.

Received: September 7, 2016; evaluated: November 28, 2016; accepted: December 5, 2016. 


\section{Introducción}

La dogmática penal se ha construido sobre la base de proponer criterios de imputación del delito a un sujeto individual de carácter corporal. Este sujeto de la imputación ha descansado en la persona humana, a quien se le atribuye capacidad para realizar el injusto de manera culpable.

El avance de los sistemas sociales, en particular de los subsistemas económicos, ha demandado la intervención de nuevos participantes en la consecución de objetivos. Uno de ellos es la organización criminal que, como estructura integrada por un número plural de personas, ha demostrado eficiencia en la ejecución del delito.

La organización delictiva, como estructura formalizada en la categoría de empresa o de manera informal, desarrolla su propio delito: el de organización, cuya entidad subjetiva (pluralidad de personas) y su orientación objetiva (plan de comisión permanente de delitos) permiten expresar su destacada actuación en la comisión del delito.

La teoría del delito y el Derecho Procesal Penal deben responder a este nuevo reto: ¿La organización criminal puede ser sujeto de imputación?

En el presente trabajo abordaremos una pregunta para el Derecho procesal: ¿La organización criminal puede ser sujeto del proceso penal? Para ofrecer respuesta, utilizaremos los principios estructurales del proceso penal que, junto con los principios políticos de dignidad humana y libertad, permitirán demostrar que el enjuiciamiento de la organización criminal representa un caso de violación al principio de igualdad, en su faceta de igualdad de trato, porque carece de la capacidad procesal específica para comparecer en el proceso y comprender, decidir y ejercer actos procesales a favor de sus intereses, como lo haría un ciudadano valido de autoconciencia.

\section{La organización criminal como sujeto del Derecho Penal}

1. El paradigma del autor individual del delito ha devenido en cuestionamientos, por cuenta de la asimetría demostrada por la ineficiencia del aparato de justicia respecto a la eficiencia de las estructuras organizadas del delito. 
Ya la Criminología había advertido sobre esa eficiencia en los fines alcanzada por las organizaciones criminales y precisó la existencia de nuevas formas de comisión del injusto penal. En puridad, la advertencia verificó que cuando la ejecución del delito articulaba un número plural de personas, medianamente organizadas en términos funcionales y con cierta estructura elaborada para la toma de decisiones, se estaba en presencia de una organización criminal con capacidad para conseguir cualquier fin que, a la manera de una empresa económica, en forma sostenida podía gestionar objetivos delictivos como utilidades de rendimiento. Por esto, según la Criminología, el fenómeno asociativo de la criminalidad comporta los mismos elementos de las antiguas organizaciones, pero evidencia su eficiencia en nuevas manifestaciones para la realización de actividades delictivas modernas. ${ }^{1}$

La categoría de delitos de organización no es nueva. Podría remontarse a la antigua Roma, cuando se hablaba de los bandoleros que asaltaban a la gente en caminos y poblaciones. ${ }^{2}$

Esta fue la génesis de una nueva categoría delictiva: la del delito de organización, que toma distancia del habitual arquetipo de comisión del delito —el del autor individual—que, sin más estructura que la de su propio plan de autor, conseguía objetivos esporádicos.

El delito de organización fue recepcionado por la política penal mediante diferentes modos de expansión penal: el del remozamiento del ya existente delito de asociación para delinquir o asociación ilícita; la creación de tipos autónomos como nuevas cualificaciones de este delito, asignadas a tradicionales delitos comunes; la incorporación de circunstancias de agravación punitiva a un buen número de delitos. ${ }^{3}$

Todas estas formas de inflación del Derecho Penal han sido de concurrente aplicación en la legislación penal, con un factor característico y es que se ha incrementado la

1 Eugenio Raúl Zaffaroni, El crimen organizado: una categorización frustrada (Córdoba: Universidad Nacional de Córdoba 1995), 251-257. En su interesante trabajo, Zaffaroni sostiene, desde la conceptualización de la categoría del "crimen organizado", que esta obedece a un concepto norteamericano de reciente aparición.

2 Guillermo Yacobucci, "Política criminal y delincuencia organizada" en El crimen organizado: desafios y perspectivas en el marco de la globalización, coord. Guillermo Yacobucci (Buenos Aires: Ábaco de Rodolfo Depalma, 2005), 25 y ss.

3 Jesús-María Silva Sánchez, "¿"Pertenencia” o 'intervención'? Del delito de "pertenencia a una organización criminal" a la figura de la 'participación a través de organización' en el delito" en Estudios penales en recuerdo del profesor Ruiz Antón, coord. Emilio Octavio de Toledo y Ubieto, Manuel Gurdiel Sierra y Emilio Cortés Bichiarelli (Valencia: Tirant lo Blanch, 2004), 1069-1070. 
tutela de bienes jurídicos como la seguridad pública, la salud pública, la vida o la libertad individual.

2. Las particularidades de esa criminalidad organizada han sido, en primer lugar, su entidad subjetiva, caracterizada por una pluralidad de personas que se agrupa en la configuración de una asociación delictiva. Al existir una sumatoria de sujetos entre los que se reparten funciones, ${ }^{4}$ se alcanza cierta organización permanente $e^{5}$ o medianamente duradera, en la que sus estructuras prestacionales se hacen eficientes en procura de un fin. Es claro que los objetivos de la organización son de factible y oportuna obtención si los roles se desempeñan por varias personas. Las organizaciones serán permanentes a partir de un estable reparto de tareas, ${ }^{6}$ en el que los roles de los sujetos que la integran o la lideran son sostenibles y tan solo resultan intercambiables los individuos que ocupan tales roles.

En segundo lugar, su orientación delictiva, esto es, la organización que converge en planes comunes. ${ }^{7}$ La agrupación se orienta a la comisión permanente de delitos, lo que sirve de punto de convergencia de voluntades y sustenta lo injusto de la asociación. La convergencia de voluntades se refiere a que, en forma duradera y no transitoria, se pretende un mismo fin, que será el de cometer delitos como una empresa criminal y tiene dentro de su objeto la realización de delitos en el futuro.

Esto permite diferenciar entre el delito de organización como asociación delictiva, las categorías de codelincuencia como la coautoría o la participación y la conspiración para cometer delito. En la coautoría, los sujetos intervienen mediante comisión conjunta, ${ }^{8}$ con una decisión común, división de tareas y una contribución efectiva de aportes prohibidos; ${ }^{9}$ en la participación se facilita el delito de otro y los sujetos hacen intervenciones individuales para cometer un delito.

Percy García Cavero, Derecho Penal Económico. Tomo II: Parte especial (Lima: Grijley, 2007), 449-450. Francisco Muñoz Conde, Derecho Penal. Parte especial (Valencia: Tirant lo Blanch, 1996), 713 y 715.

La "estabilidad", entendida como sinónimo de permanencia en la unión voluntaria y permanente de personas para conseguir un fin común, voluntariamente y mediante una actividad colectiva. Jesús Bernal Pinzón, Delitos contra la administración pública y asociación para delinquir (Bogotá: Temis, 1965), 432-436.

7 Gonzalo Quintero Olivares, "De la receptación y otras conductas afines" en Comentarios a la parte especial del Derecho Penal, coord. José Manuel Valle Muñiz (Pamplona: Aranzadi, 1996), 711.

8 Partimos de una concepción normativa de la intervención en el delito en la que se determina una competencia común por el hecho total Heiko Lesch, Intervención delictiva e imputación objetiva, trad. Javier Sánchez Gómez-Trelles (Bogotá: Universidad Externado de Colombia, 1995), 51.

9 Se hace especial relación a la llamada coautoría funcional, que exige tales elementos. Esteban Righi, Derecho Penal. Parte general (Buenos Aires: Abeledo Perrot, 2010), 382-383. 
Estas formas de intervención en el delito constituyen el paradigma del autor individual que, aun cuando obre con otros, su imputación será vista en función del aporte concreto y de la infracción al rol; ${ }^{10}$ la conspiración es un simple acuerdo para tomar parte en un hecho específico, sin organización ni permanencia para cometer delitos indeterminados, como sí sucede en el delito de organización.

En el Derecho Penal anglosajón la conspiracy es un delito autónomo y requiere concierto (agreement) y plan común (common plan) para ejecutar un designio por medios criminales. ${ }^{11}$ En el Derecho Penal continental, se entiende como evento de codelincuencia que abarca un acto preparatorio como la coautoría, distinto del delito de organización como la asociación ilícita. ${ }^{12}$

El delito de organización es independiente de los delitos que se cometen mediante la agrupación, lo que define su carácter autónomo.

Como agrupación estable, la organización delictiva deberá poseer un esquema de poder, dirección y planificación que unos diseñan y otros cumplen. Esto determina que la intervención de sus miembros podrá ser diferenciable e independiente, de acuerdo con el rol y las tareas que efectivamente se ejecuten con esa misma orientación delictiva.

Lo injusto del delito de organización se define a partir de los fines delictivos que contrae y que le diferencian de las organizaciones o asociaciones lícitas. ${ }^{13}$ En varios Derechos Penales positivos, el delito de organización, que está fundamentalmente representado en el delito de asociación ilícita, es una conducta que lesiona el derecho fundamental de asociación garantizado por la Constitución, de allí que se estime que su realización es un abuso de tal derecho. ${ }^{14}$

10 Ernst-Joachim Lampe, "Injusto del sistema y sistemas de injusto" en La dogmática jurídico-penal entre la ontología social y el funcionalismo, ed. y trad. Carlos Gómez-Jara Díez, Guillermo Orce y Miguel PolainoOrts (Lima: Grijley, 2003), 97.

11 Theresa Berlin Stuchiner, Delitos y penas en los Estados Unidos, trad. Fernando Díaz Palos (Barcelona: Editorial Bosch, 1959), 48-49; Edmundo Hendler, Derecho Penal y procesal penal de los Estados Unidos (Buenos Aires: Ad Hoc, 1996), 90-100.

12 Paradigmático, Joaquín Cuello Contreras, La conspiración para cometer el delito (Barcelona: Bosch, 1978). Una distinción con el delito de organización en Patricia Ziffer, El delito de asociación ilícita (Buenos Aires: Ad Hoc, 2005), 191-203.

13 En el ámbito español por todos, Antonio García-Pablos de Molina, Asociaciones ilícitas en el Código Penal (Barcelona: Antoni Bosch Editor, 1977). En Argentina, Ziffer, El delito de asociación ilícita, 48 y ss.

14 Es el caso del Derecho Penal español, véase Muñoz Conde, Derecho Penal, 705 y ss. 
La verificación de dichos elementos es demostrativa de la mentada eficiencia que comporta el delito de una organización, pues la comisión de los delitos-fines en forma permanente se obtiene gracias a su compleja estructura de distribución de funciones en varias manos, lo que optimiza los objetivos y garantiza la inmunidad frente a la acción de la justicia.

3. Estos datos son el insumo de una propuesta de un sector de la dogmática jurídico-penal de nuestros días que ha puesto sobre la mesa la idea de una nueva estructura de imputación en los delitos de organización.

Para este modelo, la base de la imputación no la ofrece el propio injusto de cada persona física que interviene delictivamente en el colectivo criminal, sino el injusto de la organización en sí misma. Este planteo encuentra fundamentación en la capacidad de la organización para crear riesgos en el sistema social, que pueden devenir en lesiones o puestas en peligro a bienes jurídicos. La organización criminal de naturaleza empresarial es un interesante ejemplo de antijuridicidad a partir de riesgos. La empresa como individuo participa de muchos procesos comunicativos en los mercados: se sitúa como agente económico, ${ }^{15}$ titular de un rol generador de expectativas de comportamiento respecto al resto de participantes en los mercados. A partir de su destacada intervención como sujeto que ejerce el control de recursos y de intercambio de los mismos en el mercado, se verifica su antijuridicidad en el poder sobre el mercado, cuando aprovecha la desregulación del mismo e impone su propia disciplina.

Este viraje en la estructura de imputación se mueve sobre su propio eje: el injusto que se reputa de la organización o el injusto sistémico o del sistema organizativo.

Con este sistema se pretende sustituir el paradigma de imputación de autor individual a los miembros de la organización delictiva por un modelo de imputación en el que a los integrantes de la colectividad se les atribuya responsabilidad por el injusto de la organización delictiva.

De este modo, la atribución de un hecho como obra de un miembro de la organización proviene de una transferencia de lo injusto de la organización hacia el

15 Percy García Cavero, La responsabilidad penal del administrador de hecho de la empresa: criterios de imputación (Barcelona: J. M. Bosch Editor, 1999), 58-59. 
integrante del colectivo o, de manera más sucinta, el injusto de la organización finca la imputación y la responsabilidad del auto y no el propio injusto personal de este.

Más allá de los problemas sustanciales que arroje esta propuesta, al contravenir los principios de acto, de responsabilidad personal por el hecho y el de culpabilidad, es nuestro interés verificar en este estudio si los principios estructurales del proceso penal se quebrantan si se acepta la hipótesis de que la organización criminal puede ser enjuiciada individualmente por su injusto, esto es, si la organización sería destinataria de los principios del proceso penal que garantizan los derechos y las garantías de un ciudadano en un proceso judicial.

\section{Los principios estructurales del proceso penal}

1. El sistema procesal penal es uno de los casos en los que el Estado, por medio de enunciados jurídicos, vive una relación tensionante entre la legitimación de la actuación judicial del poder punitivo y la limitación a ese poder, en procura de asegurar los valores y las libertades básicas.

Este interesante problema de habilitación del poder y contención del mismo encuentra su marco teórico en los principios jurídicos de naturaleza constitucional, que ofrecen las razones valorativas del Derecho Penal sustancial y procedimental, para comprender la fundamentación del Derecho Procesal colombiano.

La estructura y la funcionalidad del sistema procesal descansan en los principios derivados del sistema acusatorio que identifica al Derecho Procesal en Colombia. El estudio de estos principios enseñará las razones del sistema procesal para limitar el poder estatal en el escenario judicial, pese a su aplicación práctica y dinámica en el proceso, por medio de los roles de las partes en el proceso.

Para los efectos metodológicos de este trabajo, se precisará cada principio y la teoría de justicia ínsita en su fundamentación, al tiempo que lo situaremos en el texto constitucional y legal. Con esto se pretende contar con el insumo necesario para responder, en la última parte del trabajo, al problema planteado.

2. Principio acusatorio. Es un corolario del principio democrático y del principio de división de poderes, que son legatarios del modelo de Estado social y democrático de Derecho contenido en el Artículo 250 de la Constitución Política. Sobre este principio se sostiene una teoría de justicia en la que la 
dignidad humana, la libertad, la igualdad y la legalidad se encuentran a buen recaudo.

Un Estado social, de libertades y de carácter democrático legitima su modelo de justicia penal solo cuando apuesta a la configuración del sistema procesal acusatorio y rechaza la tendencia inquisitiva en su proceso. Lo acusatorio hace del sistema procesal penal un modelo de justicia en el que el ciudadano asegura sus libertades básicas, cuando un ente oficial y objetivo le da a conocer que será objeto de persecución penal en un juicio público y oral, en donde un administrador de justicia autónomo e imparcial decidirá sobre su intervención en un hecho punible.

Este relato contrae las premisas del principio acusatorio, que son: a) no puede existir proceso sin acusación, y b) quien acusa no juzga.

a) No puede haber proceso sin previa acusación. Explica la necesidad del presupuesto de una acusación para proceder al enjuiciamiento y a la condena y, con ello, a propiciar los principios de contradicción y defensa que el ciudadano llevará a su realización cuando conozca el objeto de la pretensión penal en su contra. Un ciudadano conseguirá seguridad jurídica y, en consecuencia, libertad, si es informado del contenido de la acusación.

b) Quien acusa no juzga. Descansa en los principios de imparcialidad ${ }^{16} \mathrm{y}$ de división de poderes, al suponerse que el funcionario titular de la acción penal que desarrolla las tareas de investigación y acusación no es apto para emitir una sentencia. Sus labores funcionales de la pretensión penal le impedirán ser imparcial si tuviera que decidir, cuando quiera que su interés en el proceso es uno: perseguir el delito. Para perseguir el delito, en el acto de acusación la Fiscalía aportará unos hechos que soportará con pruebas, lo que le llevará a una convicción individual de una verdad que difícilmente podrá reflexionar, cuestionar o negar si se le encomienda decidir como un juez.

Al tiempo, el juzgador no puede ser investigador, pues en su rol de administrador de justicia en el conflicto y tercero imparcial, no podría aportar hechos y pruebas de estos, porque el objeto del proceso se construye en la dialéctica del discurso

16 Juan Montero Aroca, Principios del proceso penal (Valencia: Tirant lo Blanch, 1997), 86. 
de las partes. Si el juez contribuye a la elaboración del objeto del proceso y hace aportes a la consecución de la verdad, habrá quebrado la exigencia de imparcialidad.

Una vez expresados los fundamentos de los contenidos del principio acusatorio, resulta pertinente precisar las consecuencias garantistas que de estos se desprenden y que suelen ser limitadores del poder punitivo estatal. Veamos:

i) La existencia de una acusación garantizará el conocimiento del imputado acerca de la acusación formulada (art. 8.h CPP) en el escrito de acusación (arts. 250.4 CPol y $175 \mathrm{CPP}$ ). Se proyecta así el derecho de defensa y podrá ejercerse de manera eficiente.

El acto de acusación delimitará el objeto del proceso, esto es, demarcará el sujeto y los hechos en los que se contrae la pretensión penal. El juez estará vinculado en la sentencia a circunscribirse al dato fáctico y de personas que se precisaron en el acto de acusación. Esta idea expone el principio de congruencia que, como una garantía, explica que el juez no puede dictar sentencia condenatoria por hechos distintos a los acusados ni contra personas distintas a las acusadas. De esta forma, la congruencia se relaciona con el principio de imparcialidad, al imponérsele al juzgador el deber de correspondencia entre la sentencia y el contenido de la acusación.

Sobre congruencia como garantía constitucional del proceso penal acusatorio ha expuesto la jurisprudencia constitucional:

En materia de aplicación del principio de congruencia en el contexto de un sistema penal acusatorio, se tiene que (i) se trata de un principio cardinal que orienta las relaciones existentes entre la formulación de la acusación y la sentencia; (ii) su aplicación se extiende al vínculo existente entre la audiencia de imputación de cargos y aquella de formulación de la acusación; (iii) de allí que esta última no pueda incorporar hechos nuevos, es decir, no imputados previamente al procesado; y (iv) lo anterior no significa que la valoración jurídica de los hechos deba permanecer incólume, precisamente por el carácter progresivo que ofrece el proceso penal. En otras palabras, fruto de la labor investigativa desarrollada por la Fiscalía durante la fase de instrucción, es posible, al momento de formular la acusación, contar con mayores detalles 
sobre los hechos, lo cual implica, eventualmente, modificar, dentro de unos parámetros racionales, la calificación jurídica de los hechos. ${ }^{17}$

Como se observa, la congruencia es un principio que permite armonizar otros principios adicionales al acusatorio que le dan sustento, como el de defensa y contradicción. Esto ha sido afirmado por la misma jurisprudencia citada:

Ahora bien, en materia procesal penal, el principio de congruencia adquiere una mayor relevancia debido a su íntima conexión con el ejercicio del derecho de defensa. De tal suerte que no se trata de una simple directriz, llamada a dotar de una mayor racionalidad y coherencia al trámite procesal en sus diversas etapas, sino de una garantía judicial esencial para el procesado. ${ }^{18}$

Pues bien, como lo reconoce la doctrina especializada, la correlación que debe existir entre la acusación y la sentencia configura un derivado de la vinculación judicial al objeto del proceso "y en tal sentido, cohonestada primordialmente con el principio acusatorio". ${ }^{19}$ A decir verdad, el principio de congruencia configura un elemento central de un sistema penal acusatorio, caracterizado por: i) la separación entre el órgano que investiga y acusa con aquel que falla; ii) el derecho que tiene el procesado a conocer la acusación formulada, y iii) una comprensión estricta de la prohibición de la reformatio in pejus.

Sobre el particular, merece la pena destacar que los Códigos de Procedimiento Penal alemán, italiano y portugués coinciden en resaltar la importancia: i) del establecimiento de los elementos delimitadores del objeto del proceso, de forma inequívoca, y ii) de la garantía de los derechos de defensa y de contradicción del procesado, para preservar ciertos mecanismos que, bajo estrictas condiciones, permiten introducir modificaciones a la calificación jurídica de los hechos. ${ }^{20}$

ii. En virtud de la regla iura novit curia, el juez no estará sujeto a la calificación jurídica de los hechos ni a la pena solicitada por las partes, pues el sentenciador determinará el marco jurídico de la condena con base en el principio de legalidad. Esto, empero, no deja en libertad al juez de adecuar los hechos al tipo penal en forma arbitraria, como es el caso de sancionar un hecho dos veces, con lo que

\footnotetext{
Corte Constitucional, Sentencia C-025 de 27 de enero de 2010, M. P. Humberto Antonio Sierra Porto. Corte Constitucional, Sentencia C-025 de 27 de enero de 2010.

Teresa Armenta Deu, Principio acusatorio y Derecho Penal (Barcelona: Bosch, 2003), 72.

Armenta Deu, Principio acusatorio y derecho penal, 80.
} 
infringe el principio de non bis in idem, que le prohíbe doble incriminación de un mismo dato fáctico a un mismo ciudadano (art. 29 CPol).

Con la delimitación del objeto del proceso, la necesidad de acusación se extiende a las instancias cuando se materializa el principio de doble instancia, derivado del derecho al recurso. Esto quiere decir que el conocimiento del juez de apelación estará delimitado por los hechos y los sujetos que conformaron la apelación e incluso por la calificación jurídica y la pena determinada por el juez inferior.

De ello se deriva que el juez de segunda instancia no podrá incurrir en reforma peyorativa del objeto del proceso construido por las partes, pues de hacerlo violará el principio de no reformatio in pejus.

2. Principio de contradicción. Es un derecho-garantía de carácter fundamental que encuentra basamento en la necesaria relación dialéctica que debe estructurar un proceso judicial y, por ende, un proceso penal.

Cuando el Estado plantea jurisdiccionalmente una relación contenciosa a partir del ejercicio del derecho de acción, que se concreta en el actuar el ius puniendi, se motiva al ciudadano al ejercicio de oposición a esa pretensión penal que acciona el Estado. Por ello, es dable afirmar que la contradicción es un derecho por el cual el ciudadano defiende el ejercicio de sus libertades básicas que se comprometen o podrían verse restringidas en el proceso penal.

La contradicción surge de esa relación tensionante entre la pretensión punitiva estatal y la oposición de libertad ciudadana.

El derecho de contradicción, junto al derecho de acción, será una garantía de idéntica naturaleza y de contenido igual, ${ }^{21}$ lo que muestra su afecto al principio de igualdad. Como derecho, pertenece al sujeto de la acción penal y su finalidad es la satisfacción del interés público en la administración de justicia y en la tutela del derecho del procesado, en aras de obtener la decisión del conflicto mediante la determinación de la responsabilidad penal del ciudadano. Esto lo vincula con la tutela de los principios constitucionales de dignidad humana, libertad y defensa que, al romperse, pueden ser limitados con la acción penal.

21 Paradigmático entre nosotros, Hernando Devis Echandía, Principios fundamentales del derecho procesal penal (Bogotá: ABC, 1981). 
El principio de contradicción no persigue una decisión concreta y favorable al procesado, sino una tutela abstracta y justa de las libertades restringidas al ciudadano, lo que niega la expresión de este principio como un derecho a una sentencia absolutoria para el procesado. Se afirma que el derecho de contradicción nace en el proceso penal, cuando el ciudadano adquiere la condición de imputado y se extiende en la fase del juicio oral. Con esto es posible definir el principio de contradicción con la frase: "[...] nadie puede ser condenado sin ser oído y vencido en juicio" 22 que, entre nosotros, se explicaba eficientemente cuando se afirmaba que la contradicción:

Es el derecho a ser oído en el proceso si se tiene la voluntad de hacerse oír, para tener oportunidad de alegar y probar hechos que lo favorezcan o simplemente de negar las imputaciones que se le formulen, e interponer los recursos que la ley consagra, o sea el derecho a gozar de la oportunidad procesal práctica para defenderse y de obtener mediante el proceso la sentencia que resuelva, favorable o desfavorablemente sobre esa defensa, si llega a proponerla, o si simplemente niega su responsabilidad o nada manifiesta. ${ }^{23}$

En una óptica de fundamentación, Winfried Hassemer sostiene que en el proceso penal se genera una "comprensión escénica" del caso, tanto en su fase de producción como en su elaboración final, a la que el acusado acude cuando se representan las escenas del proceso. Por ello, afirma el autor que el acusado debe ser un partícipe en la comprensión escénica. ${ }^{24}$

El más significativo modo de regulación de la comprensión para nuestra concepción constitucional es la participación del acusado en la producción de "su" caso. Se trata de un importante indicador en el seno de un no menos importante tema político: las oportunidades del particular para intervenir en la adopción de las decisiones estatales que le afecten.

La participación del acusado en el proceso de comprensión no es una exigencia derivada de la teoría de la comprensión, sino una exigencia de la Filosofía Política y de la Política Jurídica y, en consecuencia, corre mayores peligros que los demás presupuestos necesarios para la comprensión en el proceso.

\footnotetext{
Teresa Armenta Deu, Lecciones de Derecho Procesal Penal (Madrid: Marcial Pons, 2004), 36.

Devis Echandía, Principios fundamentales del Derecho Procesal Penal, 78.

Winfried Hassemer, Fundamentos del Derecho Penal (Barcelona: Bosch, 1994), 173.
} 
El Derecho Procesal realiza la idea de que la producción del caso no puede ser regular sin la posibilidad de que el acusado interfiera en ella y pueda influir argumentalmente en el proceso de comprensión. ${ }^{25}$

Con esto y dado que la contradicción suministra el espacio para el reconocimiento de oportunidades para que el procesado se defienda de la pretensión penal, es posible afirmar que en la fase de investigación, como en el juicio, es posible ejercer contradicción. Ello descansa en una comprensión del principio de contradicción que no se reduce a hacer uso del derecho a controvertir y ofrecer pruebas en el juicio, como restringidamente lo enuncia el Artículo 29 constitucional, sino que se extiende al ejercicio de las tareas de refutación durante todo el proceso, cuando se adquiere la condición de imputado (art. 290 CPP).

Contrariamente, con una visión reduccionista del principio de contradicción, la Corte Constitucional expresa que este se desarrolla en la dinámica de la prueba. Afirma:

Al respecto, recuerda la Sala que los principios de inmediación y contradicción cumplen su papel estelar y protagónico en el proceso de producción de la prueba, tarea que en el contexto del sistema acusatorio se desarrolla en la fase del juicio oral. Tal como se deriva del texto constitucional (art. 250.4) que establece las características del juicio en el sistema penal acusatorio, los principios de inmediación y contradicción técnicamente despliegan su eficacia en el momento del debate probatorio, con miras a facilitar y optimizar la actividad cognitiva propia del proceso de conocimiento que acompaña la producción de la prueba. La actitud crítica, consciente y controlada que debe asumir el juez que dirige el debate en el juicio oral, exige el contacto directo con los actores que intervienen en esa fase. ${ }^{26}$

No obstante, en un sentido amplio del principio, pueden ser varias las oportunidades para ejercer contradicción: i) al presentar observaciones al acto de imputación (art. 289 CPP) y al acto de acusación, mediante la contradicción de cargos; ii) al expresar, en este mismo acto, causales de incompetencia, impedimentos, recusaciones y nulidades (art. 339 CPP); iii) en la audiencia preparatoria, contradecir el descubrimiento probatorio (art. 356.1 CPP), rechazar o solicitar la exclusión o inadmisibilidad de las solicitudes de prueba (art. 359 CPP), descubrir y solicitar

25 Hassemer, Fundamentos del derecho penal, 173.

26 Corte Constitucional, Sentencia C-371 de 11 de mayo de 2011, M. P. Luis Ernesto Vargas Silva. 
pruebas (arts. 356.2 y 357 CPP); iv) en el juicio oral, presentar alegato de apertura y teoría del caso (art. 371 CPP), controvertir las pruebas (art. 125.4 CPP), mediante la práctica de contrainterrogatorio a los testigos de la Fiscalía e interrogando a los propios testigos (arts. 125.5 y 390 a 394 CPP) y presentar alegatos de conclusión (art. 443 CPP), y v) al formular recursos (art. 125.7 CPP) durante todo el proceso, en las oportunidades y en los casos procedentes.

Tales oportunidades son reconocidas en el Artículo 125 del Código de Procedimiento Penal, en donde consagra los allí llamados "deberes y atribuciones especiales de la defensa" para la contradicción (párr. 3 y 4, art. 29 CPol), que emergen de la norma constitucional.

3. Principio de defensa. Es un principio derivado del principio de contradicción y cuenta con varias versiones normativas en su configuración; la primera es la de principio o derecho fundamental en el inciso tercero del Artículo 29 Constitucional.

Pese a ello, el anterior enunciado no es la única norma superior que lo vierte, pues de la lectura del Artículo 2 puede afirmarse que la defensa se deriva del ejercicio del principio democrático, en su concreción de democracia participativa, cuando a los ciudadanos se les permite la "participación" en las decisiones que les afectan. Tal normativa, a más de dar sustento al principio de contradicción, se lo otorga al de defensa, como a otros del sistema procesal penal.

Este principio político que soporta el principio de defensa constituye una idea de justicia, toda vez que obliga al Estado a abrir las puertas del diálogo para que el ciudadano, que encuentra comprometidas sus libertades básicas y sobre todo su libertad ambulatoria en un proceso penal, participe del mismo y ejerza su defensa material y técnica.

Otras normas constitucionales refieren el ejercicio a la defensa, como el Artículo 30 de la Carta, en el cual se extiende al derecho a los ciudadanos de promover la acción pública de habeas corpus, para defender el derecho a la libertad ambulatoria ante una privación ilegal de la libertad por parte de las autoridades. Por su parte, el Artículo 33 constitucional expresa una faceta del derecho a la defensa, consistente en el derecho a la no autoincriminación y a la negativa de declaración incriminatoria contra familiares que conforman vínculos de consanguinidad, afinidad y de carácter civil. 
Es menester precisar cómo se estructura la idea de justicia que está detrás del principio de defensa en un sistema procesal penal. La defensa, como principio garantista del ciudadano, se entiende en dos facetas de actuación en el curso del proceso penal. Una es la faceta negativa y otra, la positiva.

1. La faceta negativa, llamada también interdicción de indefensión o prohibición de indefensión, ${ }^{27}$ tiene lugar cuando se impide al procesado conocer y rebatir, así como alegar o probar su verdad durante el proceso. Ello supone una infracción o inobservancia a una norma de procedimiento que contrae una garantía de defensa, que pone en desventaja al procesado y lo priva de oponerse a la persecución estatal.

La situación de desventaja muestra una clara relación con el principio de igualdad predicado en el proceso penal, pues se gesta un desequilibrio en la asignación y el uso de oportunidades en el proceso, lo que concluirá en una violación al principio y derecho fundamental a la defensa.

Para que la indefensión se configure deben concurrir los siguientes presupuestos: i) que se haya infringido una norma procesal; ii) que se haya limitado o privado una oportunidad a la defensa; iii) que la privación no sea imputable a quien la sufre, lo que tiene una contracara, que dicha indefensión debe ser probada por quien la soportó; iv) que la restricción de la defensa no haya sido saneada, y v) que la indefensión devenga en un resultado negativo en la sentencia.

2. En la faceta positiva, el derecho fundamental a la defensa es irrenunciable. Su finalidad dentro del diálogo del proceso penal es procurar la oposición a la restricción de las libertades básicas que supone el ejercicio del ius puniendi.

Además de ser derecho fundamental, la Corte Constitucional afirma el carácter de garantía del que se desprenden otras prerrogativas para el ciudadano. Esto dice la Sentencia C-371 de 2011:

El derecho a la defensa es una garantía universal, general y permanente que constituye un presupuesto para la realización de la justicia como valor superior del ordenamiento jurídico. Así lo estableció la Corte en la sentencia C-799 de

27 Montero Aroca, Principios del proceso penal, 142 
$2005^{28}$ en la que señaló que este derecho "surge desde que se tiene conocimiento que cursa un proceso en contra de una persona y sólo culmina cuando finalice dicho proceso," pero sin desconocer que el mismo se debe ejercer de manera oportuna y por los cauces señalados en la ley.

La Corte ha considerado que, no obstante que el legislador cuenta con un amplio margen de configuración para diseñar los diversos procesos judiciales, el derecho de defensa debe encontrarse plenamente garantizado a lo largo de todas y cada una de las etapas que conforman un proceso penal de carácter acusatorio.

En relación con el plexo de garantías que involucra el ejercicio del derecho de defensa, en el contexto de un sistema acusatorio, la corporación ha sentado las siguientes reglas:29 (i) ni en la Constitución ni en los tratados internacionales de derechos humanos se ha establecido un límite temporal para el ejercicio del derecho de defensa; ${ }^{30}$ (ii) el derecho de defensa es general y universal, y en ese contexto no es restringible al menos desde el punto de vista temporal; ${ }^{31}$ (iii) el ejercicio del derecho de defensa surge desde que se tiene conocimiento

28 La Corte revisó la constitucionalidad del Artículo 8 de la Ley 906 de 2005, que consagra el principio del derecho a la defensa. El demandante consideraba que la norma era inconstitucional, pues consagraba el derecho a la defensa como norma rectora y establecía que ese derecho solo se adquiría una vez se obtuviera la calidad de imputado, lo que va en contra del Artículo 29 de la Constitución. Uno de los problemas jurídicos que resolvió la Corte en dicha oportunidad fue "si existe violación al derecho de defensa cuando la norma acusada determina que este derecho se podrá ejercer desde el momento en el cual se adquiera la condición de imputado [...]". Después de hacer un análisis del derecho a la defensa y de señalar las posibles interpretaciones del Artículo demandado, la Corte consideró que "En este orden de ideas, la correcta interpretación del derecho de defensa implica que se puede ejercer desde antes de la imputación. Así lo establece el propio Código por ejemplo desde la captura o inclusive antes, cuando el investigado tiene conocimiento de que es un presunto implicado en los hechos. Por ello, la limitación establecida en el artículo $8^{\circ}$ de la ley 906 de 2004, si se interpreta en el entendido de que el derecho de defensa sólo se puede ejercer desde el momento en que se adquiere la condición de imputado, sería violatorio del derecho de defensa". De acuerdo con lo anterior, la Corte condicionó la exequibilidad de la expresión acusada "sin perjuicio del ejercicio oportuno, dentro de los cauces legales, del derecho de defensa por el presunto implicado o indiciado en la fase de indagación e investigación anterior a la formulación de la imputación". La Parte resolutiva de la Sentencia dice: "3. Declarar EXEQUIBLE la expresión "una vez adquirida la condición de imputado' contenida en el inciso $1^{\circ}$ del artículo $8^{\circ}$ de la ley 906 de 2004, por los cargos examinados, sin perjuicio del ejercicio oportuno, dentro de los cauces legales, del derecho de defensa por el presunto implicado o indiciado en la fase de indagación e investigación anterior a la formulación de la imputación". Corte Constitucional, Sentencia C-799 de 2 de agosto de 2005, M. P. Jaime Araujo Rentería.

29 Una relación de las principales líneas jurisprudenciales establecidas por la Corte respecto al derecho de defensa en Corte Constitucional, Sentencia C-648 de 24 de agosto de 2010, M. P. Humberto Antonio Sierra Porto.

30 Corte Constitucional, Sentencia C-799.

31 Corte Constitucional, Sentencia C-799. 
que cursa un proceso en contra de una persona y sólo culmina cuando finalice dicho proceso; ${ }^{32}$ (iv) el derecho de defensa, como derecho fundamental constitucional, es un derecho que prima facie puede ser ejercido directamente por un procesado al interior de un proceso penal; ${ }^{33}(\mathrm{v})$ el procesado puede hacer valer por sí mismo sus argumentos y razones dentro de un proceso judicial:34 (vi) el derecho de defensa se empieza a ejercer desde el momento mismo que se inicia la investigación; ${ }^{35}$ (vii) constituye una de las principales garantías del debido proceso, y representa la oportunidad reconocida a toda persona, en el ámbito de cualquier proceso o actuación judicial o administrativa, de ser oída, de hacer valer las propias razones y argumentos, de controvertir, contradecir y objetar las pruebas en contra y de solicitar la práctica y evaluación de las que se estiman favorables, así como de ejercitar los recursos que la ley otorga:;6 y (viii) la importancia del derecho de defensa, en el contexto de las garantías procesales, radica en que con su ejercicio se busca impedir la arbitrariedad de los agentes estatales y evitar la condena injusta, mediante la búsqueda de la verdad, con la activa participación o representación de quien puede ser afectado por las decisiones que se adopten sobre la base de lo actuado; ${ }^{37}$ (ix) en el contexto de los procesos penales, el derecho a impugnar la sentencia condenatoria adquiere carácter fundamental, por lo que el Estado tiene la obligación de garantizar su efectividad (Corte Constitucional, 2011). ${ }^{38}$

Como un derecho compuesto del citado plus de garantías, se comprenden dos definiciones de defensa: la defensa material y la defensa técnica, que hacen desprender un número importante de otras garantías. Veamos:

La defensa material, llamada autodefensa, descansa en la necesidad de que el ciudadano sea sujeto del proceso y no objeto del mismo, en virtud del principio de dignidad humana y que cuente con los medios y las oportunidades para enfrentar la acción penal promovida por el Estado. En consecuencia, la autodefensa es un derecho del cual puede disponer y ejercer el ciudadano y el Estado está obligado a procurar (mas no a imponer contra la voluntad de su titular) durante el proceso.

\footnotetext{
Corte Constitucional, Sentencia C-799.

Corte Constitucional, Sentencia C-994 de 29 de noviembre de 2006, M. P. Jaime Araujo Rentería.

Corte Constitucional, Sentencia C-994.

Corte Constitucional, Sentencia T-920 de 18 de septiembre de 2008, M. P. Clara Inés Vargas Hernández.

Corte Constitucional, Sentencia C-025 de 27 de enero de 2009, M. P. Rodrigo Escobar Gil.

Corte Constitucional, Sentencia C-025 de 27 de enero de 2009.

Corte Constitucional, Sentencia C-040 de 24 de agosto de 2002, M. P. Humberto Antonio Sierra Porto.
} 
La defensa material se hace explícita en garantías a favor del imputado y se describen en versión constitucional y legal. Estas son:

a) El derecho a ser informado de la acusación (art. 250.4 y 9 CPol y art. 8.h) $\mathrm{CPP}$ ). Permite que el ciudadano conozca la existencia de un proceso penal durante las etapas de indagación preliminar, cuando se le cita a interrogatorio (art. 282 CPP), se le captura (art. 303.1 CPP) o tiene noticia de que se sigue en su contra un proceso (art. 267 CPP); en la etapa de investigación, cuando se da inicio a la misma mediante el acto de imputación (art. 286 a 290 CPP) y en la etapa del juicio, con acto de acusación formal, que se concreta por la radicación del escrito de acusación y su argumentación en la audiencia de formulación de acusación. Tal acto de acusación, como acto complejo conlleva la comunicación de los hechos jurídicamente relevantes que fijan la pretensión penal (art. 337.2 CPP) y el descubrimiento de las pruebas que la soportan (arts. 337.5 y 344 CPP).

b) El derecho a guardar silencio (art. 8.c CPP). Se entiende como el derecho a no ejercer contradicción u oposición a la pretensión penal de la Fiscalía medios defensivos y que sería de concreta aplicación si el indiciado guarda silencio cuando es interrogado (art. 282 CPP), no comparece al proceso (art. 291 CPP) no asiste a alguna de las actuaciones del mismo o decide no ser testigo de su propio proceso (art. 394 CPP).

El silencio como garantía de defensa material no significa más que un derecho a la libertad del ciudadano de elegir no refutar la persecución penal en contra y por ello no puede ser utilizado por el Estado como una forma de asunción de responsabilidad o de admisión tácita de la ocurrencia de los hechos. De ahí que valerse del silencio para asimilar un indicio de culpabilidad sería una práctica estatal que anularía la eficacia de tal derecho.

Como garantía de eficacia del derecho a la defensa material, es necesario que medie el asesoramiento de un abogado, como bien lo ordena la ley (art. 8.i) CPP).

c) El derecho a no declarar contra sí mismo, a no declararse culpable ni a declarar en contra de su cónyuge, compañero permanente o parientes dentro del cuarto grado de consanguinidad, civil o segundo de afinidad. Como garantía constitucional (art. $33 \mathrm{CPol}$ ) y legal (art. 8.a) y b) CPP) propicia un mandato a los órganos de justicia de advertir, con precedencia a la toma de una declaración 
del ciudadano, de su derecho a no prestar declaración en su contra, a no declararse culpable y a no incriminar a sus parientes en los citados vínculos.

Cuando un ciudadano declara como testigo en un proceso penal que se sigue a otro ciudadano o rinde testimonio en su propio proceso (art. 394 CPP), no está obligado a extender expresiones que puedan generarle un compromiso de responsabilidad para sí o para sus parientes.

Sin que constitucional y legalmente se haga explícito cuando se sitúa en cabeza del imputado, este derecho a concede la posibilidad de mentir. ${ }^{39}$ La teoría de justicia que se desprende de ello diría que el derecho a guardar silencio y a no declarar contra sí ni contra otros procede para inocentes y culpables, en términos de igualdad de oportunidades. Quien sea inocente o culpable puede ejercer la libertad de expresión en su proceso y no estará obligado a conformarse o adherirse a la verdad de la pretensión penal. Por ello, la vigencia de esta garantía fundamental no habilita al juez para sancionar la mentira del procesado en su declaración ni para inferir culpabilidad y tan solo le autoriza para aseverar que es falsa y restarle mérito para construir la verdad de su inocencia.

d) El derecho al intérprete o traductor (art. 8.f CPP). Se relaciona con las garantías de asistencia de un abogado (art. 8.e CPP), conocido como derecho a la defensa técnica, la comunicación privada con el defensor (art. 8.g CPP) y a disponer de facilidades como el tiempo razonable para la preparación de la defensa (art. 8.i CPP).

Estas garantías se contraen en un derecho de comunicación, que permite la oralidad y la contradicción como principios del proceso que, de contera, resguardan el derecho del ciudadano a ser oído en el proceso penal. Por esto, es necesario facilitar el tiempo y los medios adecuados de comunicación entre el imputado y su defensor; esto en orden a conseguir una defensa eficiente de las libertades, en términos de igualdad en relación con el Estado — principio de igualdad de armas_ que, como hemos dicho, dispone de medios costosos a los que no accede la defensa.

La defensa técnica o llamada asistencia de un abogado es una garantía constitucional (art. $29 \mathrm{CPol}$ ) que concede el derecho a un ciudadano a ser asistido por un

39 José María Asencio Mellado, Derecho Procesal Penal (Valencia: Tirant lo Blanch, 2004). 
profesional de su confianza, designado libremente (art. 8.e CPP) o por uno asignado por el Estado, cuando el ciudadano no lo haya escogido (arts. 291 y 303.4 CPP).

En comparación con la defensa material, este derecho es de mayor relevancia, pues no puede ser excluida, lo que significa que es obligatoria y puede ser impuesta a un ciudadano. Esto quiere decir que la defensa técnica es un derecho que debe ser garantizado por el Estado, lo que deviene en un deber para el mismo de observar y procurar que el ciudadano sujeto del proceso siempre esté asistido por un defensor y que la gestión defensiva de este sea eficiente. Los órganos jurisdiccionales deberán velar porque los ciudadanos estén representados por un abogado en todas las etapas del proceso y porque su labor se desarrolle en forma idónea, lo que define la asistencia del defensor como una garantía real y efectiva y no meramente formal.

Con el fin de garantizar el principio de concentración del proceso, se afirma que la asistencia de un defensor es una exigencia estructural del mismo y es garantía de su desenvolvimiento, por lo que la designación de un defensor al ciudadano que carece de él es un deber que incumbe al órgano judicial.

Con esto, el ejercicio del derecho de contradicción, en su expresión técnica mediante el uso de los mecanismos procesales para formular oposición a la persecución penal (art. $125 \mathrm{CPP}$ ) podrá hacerse efectivo con la asistencia de un profesional del Derecho.

\section{El quiebre de los principios políticos de la dignidad y la libertad}

1. Aceptado el rol de procesado en cabeza de la organización criminal y, con ello, que sea destinataria de los derechos y las garantías derivados de los principios de acusación, contradicción y defensa, debe advertirse que la teoría de justicia a la que apuestan estos axiomas — que descansa en los principios políticos de la dignidad humana y la libertad — fuerza a una crisis de la intervención procesal de este sujeto.

La crisis en materia procesal encuentra lugar común en el aspecto sustancial, por la carencia de autoconciencia de una organización para el ejercicio de acciones libres, para contrariar el ordenamiento jurídico, cuando se ejecuta una conducta culpable — capacidad de culpabilidad—, como para el ejercicio de actuaciones procesales que requieren de la conciencia, propia de la persona humana, para elegir el destino de su proceso. 
Tanto el Código Penal (arts. 1 y 11) como el Código de Procedimiento Penal (arts. 1 y 2) consagran los principios de dignidad humana y libertad, que entienden al destinatario de las normas en el sistema penal como persona, en cuanto digna y libre ante el sistema penal. Quiere decir que si el eje del sistema jurídico-penal es la persona, esta se asumirá como un sujeto al que se respeta su dignidad y libertad. Por esto, es pertinente conocer el contenido y el alcance de tales principios, a fin de verificar si contraen el concepto de autoconciencia, del que parecen carecer las organizaciones como sujetos procesales.

2. Principio de dignidad humana. La persona humana es intangible, no determinable, no instrumentalizable y respetable en cuanto a su autonomía individual. Estas son las premisas que integran el derecho de la dignidad humana.

En cuanto derecho de carácter universal, la dignidad de la persona asume la condición de principio fundante de todo Estado que se proclame social y democrático de Derecho, como es el caso colombiano. El Artículo 1 de la Carta instituye este modelo estatal en respeto de este principio. Asimismo, asume el estatus de derecho fundamental por cuenta de su omnipresencia en los derechos fundamentales individuales (arts. 11 a 35 CPol) y sociales (arts. 42 a 67 CPol). También se aviene como norma rectora del sistema penal por cuenta de su configuración en el Artículo 1 del Código Penal —Ley 599 de 2000—y los Códigos de Procedimiento Penal —Ley 600 de 2000 y Ley 906 de 2004-.

El principio de la dignidad humana se explica mediante su connotación negativa, esto es, al indicar los actos que se prohíben por ser violatorios de la persona en cuanto digna. Así, se sostiene que:

La persona debe ser respetada en su autonomía individual, pues está destinada a la libre elección de acciones o planes de vida, así como a la adopción de planes de excelencia, basada en su moral autorreferente, que se explica en las razones de su conciencia, convicción y creencias. De este modo, "los individuos tienen esta libertad básica cuando están en libertad de promover sus intereses morales, filosóficos o religiosos". ${ }^{40}$

40 John Rawls, Teoría de la justicia (Ciudad de México: Fondo de Cultura Económica, 1997), 193. En alusión a la autonomía, como expresión del querer propio de los individuos, véase Gustav Radbruch, Filosofía del Derecho (Madrid: Revista de Derecho Privado, 1944), 60. Desde el principio de autonomía individual, Carlos Santiago Nino, Ética y derechos humanos (Barcelona: Ariel, 1989), 408 y ss. 
Ejemplo de ello es que los actos de investigación que se desarrollan en el proceso penal no deben injerir en derechos fundamentales como la intimidad personal y, si lo hacen, como en los casos de registros, allanamientos o interrogatorios, deben estar informados de la proporcionalidad y necesidad para su materialización.

La persona es inviolable, de ahí que se prohíba su instrumentalización para la realización de fines ajenos, de otras personas o del Estado. De tal manera, como titular de derechos y obligaciones, el individuo no puede ser cosificado o utilizado como medio para la consecución de fines distintos a los suyos. Esto quiere decir que si a los individuos se les imponen sacrificios o privaciones a sus derechos para su propio beneficio, no se les cosifica. Esto se explica con el imperativo categórico kantiano de que "los fines de un sujeto que es un fin en sí mismo, tienen que ser también, si es que esta concepción tiene pleno efecto en mí, en la medida de lo posible, mis fines". ${ }^{41}$

Tal axioma contraría el utilitarismo, que sostiene obtener la utilidad social a costa del sacrificio de un individuo sin importar la distribución de dicha utilidad ni la compensación del individuo afectado. Un ejemplo es la detención preventiva como medida de aseguramiento: debe cumplir los fines constitucionales de asegurar la comparecencia del imputado al proceso y garantizar el cumplimiento de la pena en caso de condena, sin convertirse en una herramienta pedagógica del sistema penal para enseñar a la colectividad el resultado de comparecer a un proceso en condición de imputado.

La persona no podrá ser sometida a penas o tratos inhumanos, degradantes o discriminatorios. En el marco del sistema procesal penal, esto se identifica con la clásica figura de proscripción de la tortura como procedimiento de investigación ${ }^{42}$ y con la moderna prohibición del polígrafo como sistema de interrogatorio.

3. Principio de libertad. Las libertades deben ser idénticas para cada miembro de la sociedad, pero el hecho de que las personas naturales puedan ser libres o no dependerá de las restricciones dadas por el Derecho.

Tales restricciones son de índole normativa o judicial. Las primeras establecen reglas de mandatos o prohibiciones y las segundas, coerciones a esas libertades.

41 Emmanuel Kant, Fundamentación de la metafísica de las costumbres (Ciudad de México: Porrúa, 2010), 86-87.

42 Paradigmático, Cessare Beccaria, De los delitos y de las penas (Bogotá: Temis, 1994). 
El ejercicio de las libertades básicas está especificado en Derecho y esto resulta positivo al disfrute de las mismas, es decir, cuanta mayor especificidad de las limitaciones a la libertad, más garantía de un sistema de libertades. Esto genera la garantía de seguridad para el ciudadano que conocerá si una norma o institución le restringe su libertad.

El Derecho Penal es el sistema social en el cual se restringen más sensiblemente las libertades y esto sucede en dos escenarios: el legislativo y el judicial. En el legislativo, mediante las normas, se limita la extensión de las libertades ciudadanas cuando se comunica al destinatario de la norma la consecuencia punitiva de ejercer la libertad en afectación de los bienes jurídicos ajenos. En el judicial, por medio de las decisiones de un juez durante el proceso, cuando se restringen libertades con fines provisorios o definitivos.

Al Derecho Procesal le interesa el escenario judicial, pues en este se materializan las limitaciones a las libertades que en el momento legislativo fueron advertidas con las normas.

En el momento judicial, las libertades básicas corporales e incorpóreas se ven comprometidas. Los ciudadanos ceden en sus libertades como derechos constitucionales: a la libertad ambulatoria o de locomoción (art. 28), a su libre desarrollo de la personalidad (art. 16), a su libertad de conciencia (art. 18), a su libertad de expresión (art. 20), a su libertad económica (arts. 26 y 333) y a su autonomía individual (arts. 1 y 5 ).

En el marco del derecho a castigar que detenta el Estado, estas libertades se restringen legítimamente, en orden a proteger bienes jurídicos. Con esto, puede expresarse que el respeto al principio de libertad que conlleva las libertades básicas relacionadas implica que la libertad solo puede ser restringida en favor de la libertad en sí misma. Lo anterior descansa en el principio de mínima intervención, que se explica en la menor actuación del ius puniendi en las libertades ciudadanas, tanto en la limitación de libertades dada por la conminación que se realiza con la amenaza que emerge de la pena en los tipos penales, como en la aplicación de tales penas por los jueces en el momento de dictar sentencia.

En el Derecho Procesal Penal (art. 295 Ley 906 de 2004), se desarrolla esa mínima intervención desde la lógica de que la libertad es la regla y su restricción la excepción, lo que conduce a que durante el curso del proceso penal, quienes actúan el 
derecho a castigar deben procurar una menor afectación de las libertades básicas comprometidas en el enjuiciamiento.

Esta máxima de mínima restricción de la libertad halla un paradigma de referencia en la afectación de la libertad de mayor injerencia en el proceso: la libertad ambulatoria —conocida constitucionalmente como libertad de locomoción- y a la que se alude en su contenido el Artículo 2 del Código de Procedimiento Penal.

Este concepto de libertad es el paradigma de afectación en el enjuiciamiento penal y es también el de mejor regulación en cuanto a su restricción, por lo que se genera toda una doctrina que desarrolla las razones y los presupuestos de la privación de la libertad en sus diferentes eventos, como la captura, la detención preventiva (art. 307.A.1 y 2 CPP) y la pena de prisión (art. 37 CP).

Bien se afirma la incidencia de la libertad cuando, en el marco del principio acusatorio, al ciudadano se le aseguran sus libertades básicas al permitírsele ejercer contradicción a la acusación estatal mediante el derecho a la defensa, ya sea de manera activa construyendo la verdad de su inocencia, guardando silencio o renunciando al derecho a la autoincriminación.

3. Es indudable que para la materialización de los derechos y las garantías procesales en un Estado social y democrático de Derecho se requiere autoconciencia y esta es un atributo de la dignidad y libertad personales. Tal autoconciencia es la que permite predicar la capacidad para estar en juicio, es decir, para ser imputado en un procedimiento penal. ${ }^{43}$

La capacidad procesal se entiende como capacidad general para asumir el rol de imputado en un enjuiciamiento penal y depende de la capacidad penal para realizar un injusto culpable, lo que deviene en la llamada incapacidad de acción. Como explicación del apotegma clásico societas non delinquere postest, encuentra hoy inmensa oposición por quienes admiten el rubro de la responsabilidad penal de las personas jurídicas. ${ }^{44}$

43 Julio B. J. Maier, Derecho Procesal Penal. Tomo II Parte General. Sujetos procesales (Buenos Aires: Editores del Puerto, 2013), 202.

44 En Derecho Penal continental, véase Carlos Gómez-Jara Díez, ed., Modelos de autorresponsabilidad penal empresarial. Propuestas globales contemporáneas (Bogotá: Universidad Externado de Colombia, 2008). En Argentina, ver David Baigún, La responsabilidad penal de las personas jurídicas (Buenos Aires: Depalma, 2000). 
Otra es la capacidad específica, consistente en la aptitud para hacer presencia física en el procedimiento y realizar sus actos jurídicos, esto es, tomar decisiones acerca del comportamiento procesal y de ejecutarlas. ${ }^{45}$

Esta aptitud concreta para cometer actos jurídicos válidos implica, al igual que el Derecho Civil, ciertas exigencias de parte del sujeto de derecho. En el primer caso se requerirá la presencia corporal del procesado, la necesaria capacidad psíquica para comprender el acto procesal que realiza con su intervención (capacidad intelectiva), capacidad para tomar decisiones procesales (capacidad de discernimiento) y capacidad para llevar a cabo tales decisiones (capacidad de voluntad). ${ }^{46}$

En línea con estas capacidades para ejecutar actos procesales, puede indicarse que los principios del proceso penal serán pasibles de quebrantamiento, si se ignora el contenido psíquico de la capacidad específica para ser imputado en un proceso penal y esto se demuestra al revisar las exigencias del proceso penal:

i) La presencia física del procesado es necesaria para materializar el principio de acusación. La comparecencia del procesado garantizará su conocimiento del contenido y alcance del acto de acusación (art. 8.h CPP), formulado con el escrito de acusación (arts. 250.4 CPol y 175 CPP) y consigue su seguridad jurídica respecto a la imputación fáctica y la imputación jurídica que estructuran la acusación, para proyectar así el derecho de defensa, que podrá ejercerse de manera libre y eficiente.

Es necesaria su presencia para el ejercicio del principio de contradicción, esto es, para ser oído en las audiencias del proceso. Resulta imprescindible su intervención directa en actos que implican renuncia a la garantía de no autoincriminación —como la aceptación de la imputación, la aceptación de un preacuerdo o negociación con la Fiscalía — o que procuren la humanización de la justicia — como la celebración del principio de oportunidad - en los cuales su expresión oral es personalísima y genera la legalidad y validez de tales actos.

El ejercicio de la defensa material o autodefensa del procesado precisa la intervención física del procesado en el desarrollo de la etapa del juicio. Uno de estos casos será cuando el acusado decide renunciar a la garantía de guardar silencio y declara en su propio juicio, en donde se requiere su presencia para prestar juramento y atestar.

$45 \quad$ Maier, Derecho Procesal Penal, 204.
$46 \quad$ Maier, Derecho Procesal Penal, 215. 
ii) El procesado debe tener capacidad para comprender el contenido y el alcance de los actos procesales que le afectan, como el acto de acusación y el de imputación de cargos, que le permitan conocer su derecho de ejercer contradicción y su defensa en juicio.

iii) Comprendidos los actos de imputación y acusación, el procesado podrá decidir si ejerce o no contradicción a la acción penal y determinar cuál será el alcance de su derecho de defensa.

iv) La capacidad de obrar o de voluntad le permitirá al procesado renunciar a contradecir la imputación y la acusación, buscar un proceso abreviado en el que podrá allanarse a los cargos imputados, celebrar un acuerdo con la Fiscalía o perfeccionar un principio de oportunidad, intervenciones que, de manera personal y con aptitud psíquica, solo deberá efectuar el procesado. En otro caso, si decide ejercer su defensa en juicio y preservar la presunción de inocencia, requerirá una actuación personal y consciente.

Si bien es cierto que la ley procesal no exige una capacidad psíquica especial para el individuo procesado, sí es necesaria la madurez y la capacidad mental de una persona libre, para que comprenda la imputación, discierna y obre en consecuencia. Tal capacidad no se suple por el obligatorio acompañamiento de un defensor técnico que, aun cuando es necesario para la validez de todas las audiencias, no puede subrogar la autonomía individual del procesado para decidir sobre el ejercicio de la contradicción y defensa en su enjuiciamiento. ${ }^{47}$

De esta manera, se estima que la organización criminal no cuenta con la capacidad específica para el ejercicio de las garantías y los derechos procesales contraídos en los principios del proceso penal, pues la ausencia de autonomía limita su posibilidad de dirigir y ejercer consciente y libremente los actos procesales.

La admisión de la intervención en juicio de una organización criminal reñiría con otro principio político del Derecho Penal como es el de igualdad. Pese a que existen iguales oportunidades procesales para las partes, la diferencia en su ejercicio lesionará la llamada igualdad de trato, que dispone que la ley debe tratar igual a las personas sin discriminaciones injustificadas. Esto se traduce en un "principio

47 Maier, Derecho Procesal Penal, 214. 
de procedimiento", ${ }^{48}$ consistente en que si los individuos son iguales, ninguno debe tener un tratamiento preferencial, a menos que se tengan razones para ello.

En materia procesal, durante el curso del proceso, las partes deben gozar de iguales oportunidades para la promoción de sus intereses, lo que fundado en la máxima audiatur ex altera parts se manifiesta como una especie del principio iusfundamental de igualdad de los ciudadanos ante la ley (art. $13 \mathrm{CPol}$ ).

Esta faceta de la igualdad demandará de la ley y de la instancia judicial un tratamiento igual sobre tópicos que responden a situaciones iguales. De otra manera, se diría que la igualdad de trato es una forma de justicia que reclama del sistema procesal penal un trato similar a casos similares. Esto se define con claridad en el principio de imparcialidad, tan cercano al de igualdad en materia procesal.

La igualdad de trato será una regla que optimiza la no discriminación de las personas en el proceso penal para trascender hacia una igualdad material, en la cual las diferencias de autenticidad individual de los ciudadanos no resulten atendibles en el momento de administrar justicia.

Una forma procedimental de la igualdad reclama una consideración igual de los destinatarios de la norma procesal, tanto en su configuración como en su aplicación judicial.

Empero, no existe "igualitarismo" alguno que reduzca absolutamente el principio de diferencia que se infiere de la desigualdad de capacidades de los individuos, pese a que el Estado utilice reglas como la de igualdad de trato. De tal modo, la igualdad será un principio de justicia que, como ideal, pretende optimizar la asignación de oportunidades de manera racional y proporcionada.

Entonces, si se acepta a la organización criminal como sujeto con igualdad de oportunidades dentro del proceso penal, se acudirá a una constante desigualdad, pues además de no ser un sujeto pasible de la pena privativa de la libertad y no cumplirse alguna función derivada de esta clase de sanción, se le avocará a un tratamiento procesal distinto en el que no tendrá conciencia para controlar el destino de sus acciones procesales.

48 Rawls, Teoría de la justicia, 458. 


\section{Referencias}

Armenta Deu, Teresa. Lecciones de Derecho Procesal Penal. Madrid: Marcial Pons, 2004. Armenta Deu, Teresa. Principio acusatorio y Derecho Penal. Barcelona: Bosch, 2003.

Asencio Mellado, José María. Derecho Procesal Penal. Valencia: Tirant lo Blanch, 2004.

Baigún, David. La responsabilidad penal de las personas jurídicas. Buenos Aires: Depalma, 2000.

Beccaria, Cessare. De los delitos y de las penas. Bogotá: Temis, 1994.

Berlin Stuchiner, Theresa. Delitos y penas en los Estados Unidos. Traducido por Fernando Díaz Palos, Barcelona: Bosch, 1959.

Bernal Pinzón, Jesús. Delitos contra la administración pública y asociación para delinquir. Bogotá: Temis, 1965.

Corte Constitucional. Sentencia C-040 de 24 de agosto de 2002. M. P. Humberto Antonio Sierra Porto.

Corte Constitucional. Sentencia C-799 de 2 de agosto de 2005. M. P. Jaime Araujo Rentería. Corte Constitucional. Sentencia C-994 de 29 de noviembre de 2006. M. P. Jaime Araujo Rentería. Corte Constitucional. Sentencia T-920 de 18 de septiembre de 2008. M. P. Clara Inés Vargas Hernández.

Corte Constitucional. Sentencia C-025 de 27 de enero de 2009. M. P. Rodrigo Escobar Gil. Corte Constitucional. Sentencia C-025 de 27 de enero de 2010. M. P. Humberto Sierra Porto. Corte Constitucional. Sentencia C-648 de 24 de agosto de 2010. M. P. Humberto Antonio Sierra Porto.

Corte Constitucional. Sentencia C-371 de 11 de mayo de 2011. M. P. Luis Ernesto Vargas Silva. Cuello Contreras, Joaquín. La conspiración para cometer el delito. Barcelona: Bosch, 1978. Devis Echandía, Hernando. Principios fundamentales del Derecho Procesal Penal. Bogotá: ABC, 1981.

García Cavero, Percy. Derecho Penal Económico. Tomo II: Parte especial. Lima: Grijley, 2007. García Cavero, Percy. La responsabilidad penal del administrador de hecho de la empresa: criterios de imputación. Barcelona: J. M. Bosch Editor, 1999.

García-Pablos de Molina, Antonio. Asociaciones ilícitas en el Código Penal. Barcelona: Antoni Bosch Editor, 1977.

Gómez-Jara Díez, Carlos, ed. Modelos de autorresponsabilidad penal empresarial. Propuestas globales contemporáneas. Bogotá: Universidad Externado de Colombia, 2008.

Hassemer, Winfried. Fundamentos del Derecho Penal. Barcelona: Bosch, 1994.

Hendler, Edmundo. Derecho Penal y Procesal Penal de los Estados Unidos. Buenos Aires: Ad Hoc, 1996.

Kant, Emmanuel. Fundamentación de la metafísica de las costumbres. Ciudad de México: Porrúa, 2010. 
Lampe, Ernst-Joachim. "Injusto del sistema y sistemas de injusto" en La dogmática jurídicopenal entre la ontología social y el funcionalismo, editado y traducido por Carlos GómezJara Díez, Guillermo Orce y Miguel Polaino-Orts, 97-179. Lima: Grijley, 2003.

Lesch, Heiko. Intervención delictiva e imputación objetiva. Traducido por Javier Sánchez Gómez-Trelles. Bogotá: Universidad Externado de Colombia, 1995.

Maier, Julio B. J. Derecho Procesal Penal. Tomo II: Parte general. Sujetos procesales. Buenos Aires: Editores del Puerto, 2013.

Montero Aroca, Juan. Principios del proceso penal. Valencia: Tirant lo Blanch, 1997.

Muñoz Conde, Francisco. Derecho Penal. Parte especial. Valencia: Tirant lo Blanch, 1996.

Nino, Carlos Santiago. Ética y derechos humanos. Barcelona: Ariel, 1989.

Quintero Olivares, Gonzalo. "De la receptación y otras conductas afines" en Comentarios a la parte especial del Derecho Penal, coordinado por José Manuel Valle Muñiz, 695-715. Pamplona: Aranzadi, 1996.

Radbruch, Gustav. Filosofía del Derecho. Madrid: Revista de Derecho Privado, 1944.

Rawls, John. Teoría de la justicia. Ciudad de México: Fondo de Cultura Económica, 1997. Righi, Esteban. Derecho Penal. Parte general. Buenos Aires: Abeledo Perrot, 2010.

Silva Sánchez, Jesús-María. "¿"Pertenencia" o "intervención”? Del delito de "pertenencia a una organización criminal" a la figura de la "participación a través de organización" en el delito" en Estudios penales en recuerdo del profesor Ruíz Antón, coordinado por Emilio Octavio de Toledo y Ubieto, Manuel Gurdiel Sierra y Emilio Cortés Bichiarelli, 1067-1096. Valencia: Tirant lo Blanch, 2004.

Yacobucci, Guillermo. "Política criminal y delincuencia organizada" en El crimen organizado: desafios y perspectivas en el marco de la globalización, coordinado por Guillermo Yacobucci, 25-71. Buenos Aires: Ábaco de Rodolfo Depalma, 2005.

Zaffaroni, Eugenio Raúl. El crimen organizado: una categorización frustrada. Córdoba: Universidad Nacional de Córdoba, 1995.

Ziffer, Patricia. El delito de asociación ilícita. Buenos Aires: Ad Hoc, 2005. 